\title{
Intelectuales cubanos al servicio de la revolución
}

Alexia Massholder

Resumo: No presente trabalho recorro aos testemunhos de intelectuais cubanos com o objetivo de colocar algumas linhas para refletir sobre as formas possíveis de conceber a relação entre o intelectual e a revolução.

Palavras-chave: Intelectuais; Revolução; Cuba.

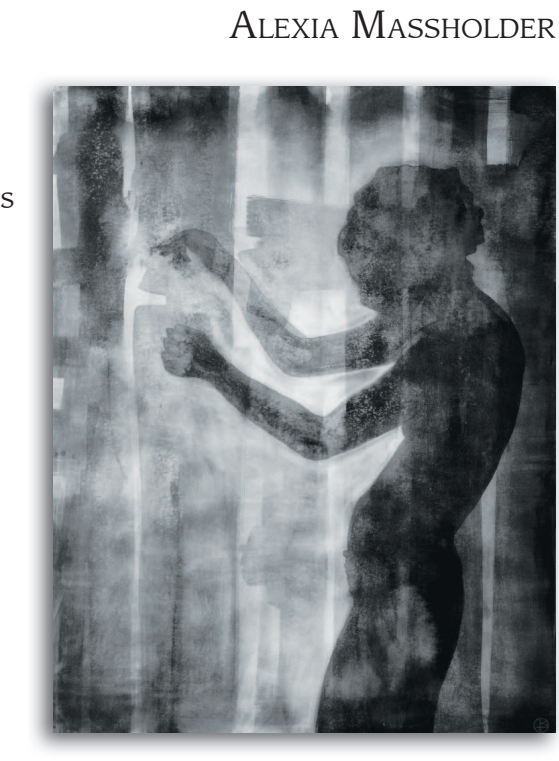

\section{Cuban intellectuals at the service of revolution}

Abstract: In this paper I refer to testimonies of Cuban intellectuals in order to put forward some possible ways of conceiving the relationship between the intellectual and the revolution.

Keywords: Intellectuals; Revolution; Cuba.

\section{Alexia Massholder}

Professora de História da Universidade de Buenos Aires. 


\section{INTRODUCCIÓN}

No maltratéis a los heterodoxos, que ellos serán los que salvarán la doctrina cuando los ortodoxos claudiquen.

(Aurelio Alonso, en La Habana, 8.11.2010)

Muchas han sido las reflexiones acerca de la función del intelectual en la lucha por la transformación radical de la sociedad. Pero ¿qué es lo que pasa cuando esa transformación se produce? ¿Cuál es el papel que los intelectuales juegan una vez que la revolución socialista llega?

Según Claudia Gilman (2003, p. 150), la problemática sobre la noción de compromiso y el papel del intelectual revolucionario inspiró el surgimiento del mito de la transición. Dicho mito, escribe la autora, puede considerarse una ficción contenedora de la brecha simbólica entre la realidad y las expectativas puestas en ella. Las indefiniciones propias de este momento de transición en lo referente a los programas concretos, el lugar del intelectual en el proceso revolucionario, entre tantas otras indefiniciones, generaron un clima cultural particularmente complejo en el que la especificidad de rol del intelectual en la construcción del socialismo no encontró patrones previos en los cuales asentarse. ${ }^{1}$

En el presente artículo recorremos a los testimonios de cuatro importantes intelectuales cubanos - Aurelio Alonso, Juan Valdés Paz, Roberto Fernández Retamar y Fernando Martínez Heredia con el objetivo de plantear algunas líneas de reflexión sobre formas posibles de concebir la relación entre el intelectual y la revolución. El período abordado contempla los años de formación de los intelectuales, previos al triunfo de la Revolución Cubana, hasta el inicio de la década de 1970 en la que, como veremos, comienza un proceso con características diferentes a los de la década anterior.

\footnotetext{
1 Gilman (2003, p. 154) explica que el mito de la transición resultó avalado por la autoridad del Che Guevara en su célebre texto El socialismo y el hombre en Cuba. Allí, Guevara se refiere al proceso de transición cubano como una fase no prevista por Marx en el primer período de transición del comunismo o de la construcción del socialismo. La revolución conduciría a una sociedad ideal y ésa era la premisa del futuro. Para casi todos los hombres, exceptuando a los más ejemplares, el problema residía en el difícil entretanto.
} 
La hipótesis que recorre este artículo es que la relación entre ortodoxia y heterodoxia, lejos de ser una relación excluyente, se convirtió en el caso cubano en un vínculo dialéctico que permitió que la intelectualidad revolucionaria toda, ortodoxa y heterodoxa, acompañara el proceso revolucionario en su larga, contradictoria y apasionante vida.

\section{LAS TRAYECTORIAS PREVIAS}

La formación de los personajes entrevistados revela recorridos marcadamente diferentes, producto de la clase social de origen y el contexto familiar. Aurelio Alonso, nacido en 1939, provenía de una familia burguesa, con un buen pasar y que le permitió dedicarse casi con exclusividad a su formación.

Primero colegio de curas, Hermanos Maristas, una formación católica. Después por voluntad propia pasé a estudiar en el instituto público el bachillerato, el Instituto de la Víbora, que tenía muy buena fama. Además era en el barrio donde vivía. Tenía buena fama porque tenía un claustro muy bueno, la enseñanza pública en Cuba tenía calidad, y nosotros teníamos un claustro muy bueno en el Instituto de la Víbora, muchos de ellos han sido profesores después del triunfo de la Revolución muy importantes de historia, de distintas materias. Y bueno, quedaron en Cuba muchos de ellos (ALONSO, 2010a). ${ }^{2}$

Por su parte, Juan Valdés Paz provenía de una familia mucho más modesta en la que hubo que priorizar el trabajo:

No me dejaban ni siquiera estudiar el bachillerato, no me podía dar el lujo de estar cinco años. Terminaba a los veinte años el bachillerato, no tenía ninguna calificación para nada, no poder trabajar [...] tu estudias el bachillerato para seguir una carrera universitaria [...] empecé a estudiar en un tecnológico y a hacer una especie de bachillerato autodidacta (VALDÉS PAZ, 2010). ${ }^{3}$

Roberto Fernández Retamar, al igual que Alonso, provenía de una familia cuya posición económica le permitió realizar sus estudios universitarios, en los que se vinculó a algunas agrupa-

2 Aurelio Alonso, 71 años, subdirector de la Revista Casa de las Américas. Las citas corresponden a dos entrevistas realizadas por la autora en la ciudad de La Habana, los días 1 (a) y 8 (b) de noviembre del 2010.

3 Juan Valdés Paz, 72 años, sociólogo y miembro de la Unión de Escritores de Cuba. Las citas corresponden a la entrevista realizada por la autora en la ciudad de La Habana, el día 12 de noviembre del 2010. 
ciones de izquierda. Una primera implicancia de la formación en los orígenes de clase es que tanto Retamar como Alonso, de familias sin urgencias económicas, pasaron como alumnos o como docentes por instituciones norteamericanas. Alonso, recuerda: "Mis padres deciden mandarme a Estados Unidos a estudiar. A estudiar lo que a mi padre le interesaba que estudiara que era business administration".

Y en el caso de Retamar:

Había sido profesor entre el año '57 y el año '58 en la Universidad de Yale. En los Estados Unidos, tenía una invitación de la Universidad de Columbia, en Nueva York, para ir a ser profesor allí, cuando Nueva York es una ciudad que a mí me gusta mucho desde que la visité cuando tenía 17 años (RETAMAR, 2010). ${ }^{4}$

Este vínculo con los Estados Unidos es clara expresión de la situación cubana antes de la revolución. La penetración material y cultural norteamericana en la isla hacía de las instituciones educativas del norte una referencia para las clases medias cubanas. Sin embargo, la creciente represión de la dictadura de Fulgencio Batista "empujó" a muchos de ellos, como estudiantes, a comenzar a participar políticamente en la "resistencia", especialmente luego del asalto al Moncada, en donde la dictadura mostró su perfil más sanguinario.

Como consecuencia de los estudio bajo la dictadura, ambos ingresaron a la política desde las casas de estudio. Alonso, desde el bachillerato, en momento en que la universidad estaba ya cerrada por el creciente conflicto de una situación "pre revolucionaria", ingresó a las luchas del movimiento estudiantil contra Batista. Y Retamar, nacido en 1930 y ya en esa época en la universidad.

Me vinculé a grupos de izquierda que había en la universidad. La Federación Estudiantil Universitaria tenía una serie de comités además, para distintas cosas positivas, contra la discriminación racial, a favor de la República Española, etcétera. Yo pertenecí a esta última, y cuando en diciembre, creo, de 1949 visitaron uestes franquistas en misión política, yo participé como otros compañeros en un boicot que se le hizo a una conferencia que iban a dar y eso terminó cómo tenía que terminar y algunos de nosotros fuimos presos [...] era difícil para quienes nos

4 Roberto Fernández Retamar, 81 años, presidente de la Casa de las Américas. Las citas corresponden a la entrevista realizada por la autora en la ciudad de La Habana, el 10 de noviembre del 2010. 
formamos digamos en la década del ' 40 , a raíz de la terminación de la llamada Segunda Guerra Mundial que la política no entrara de alguna manera en nuestra vida.

Valdés Paz, por su parte, ingresó en su condición de trabajador.

Salí a la calle, adolescente pobre, y tenía dos opciones, estudiar o trabajar, y decidí trabajar y después estudiar [...] Muchos patrones aprovechaban la circunstancia de que había caído preso [...] para deshacerte de ti. En este caso más porque yo estaba involucrado en una lucha sindical. Había una legislación batistiana que favorecía eso [...] te podían separar del trabajo por motivos políticos.

Esa fue la instancia en la que conoció a Retamar:

El trabajo alternativo que me apareció fue de maestro en una academia del padre de Roberto Fernández Retamar [...] el padre de Retamar era profesor en escuela de comercio, y tenía una academia privada que preparaba alumnos para el ingreso [...] y ahí paré yo de profesor, profesor improvisado porque yo tenía 19 años. Oportunidad en que conocí a Retamar, a Roberto [...] apareció un tipo de actividad que no había pensado, ser un docente (VALDÉS PAZ, 2010).

\section{EL TRIUNFO DE LA REVOLUCIÓN}

Aquellas diferencias iniciales en la formación encuentran con el triunfo de la revolución una serie de desafíos planteados por la coyuntura política que tendieron a colocar a todos en una misma situación: ponerse al servicio de las necesidades del proceso naciente. Las dimensiones de lo que se estaba viviendo tendieron a trastocar lo que venían siendo trayectorias más o menos orientadas hacia ciertos objetivos, con un cierto nivel de planificación. Así, las individualidades quedaron subordinadas a contribuir en el proceso colectivo de edificación del socialismo.

Retamar, por ejemplo, había recibido en aquel momento una invitación como docente en una casa de estudios norteamericana. Pero, al triunfo de la revolución...

Decidí declinar esa honrosa invitación y quedar en Cuba a servir a la Revolución. De manera que a partir de ese momento en forma fuerte la política entró en mí. Y aunque soy esencialmente un escritor, no soy indiferente a las cuestiones políticas como es natural. Alonso, que se encontraba estudiando en los Estados Unidos, permaneció unos meses más fuera del país.

Tenía la posibilidad de apresurando alguna carrera tener un título básico [...] no el licenciado, pero sacando las asignaturas 
básicas que me faltaban, un semestre, para volver con algo, un papel por lo menos [...] que me sirviera para buscar trabajo. Entonces vine en julio del '59. Pero yo ya la primera mitad del ' 59 fue casi como si la viviera aquí, porque mi padre me mandaba incluso la prensa diaria, El Hoy.

Si bien todos los entrevistados habían coincidido en su repudio hacia la dictadura de Batista celebraban el triunfo de la revolución, no es menos cierto que durante los primeros meses no se tenía un claro panorama de hacia cómo serían los primeros pasos del nuevo gobierno. Cuando Alonso regresa a Cuba, recuerda:

Tampoco venía muy convencido de todo, yo venía a ver qué cosa era lo que se estaba [...] yo siempre dije que fue la atmósfera de libertad, una libertad egoísta en el sentido que me dé la gana. No, no, yo sentí que yo estaba en un país en el cual había una dignidad distinta, y había una posibilidad distinta, y había, no se, algo, que le permitía a uno enorgullecerse.

Pero la nueva situación afectaba también a aquellos que, por su posición económica, debían reacomodarse a las nuevas exigencias del país. Muchos cubanos de clase media y del sector profesional abandonaron el país por no estar dispuestos a ceder ciertos beneficios o por desacuerdo con los planteos que comenzaba a realizar el nuevo gobierno revolucionario. En palabras de Alonso:

Yo soy alguien que regresa. Yo no soy alguien que se jugó la vida en el país. Soy un burgués, yo soy de la clase perdedora, aunque no sea del pensamiento, pero soy de la clase perdedora. Ya mi padre es afectado económicamente y tengo que empezar a trabajar en cuanto regreso.

El triunfo de la revolución implicaba, entre tantas otras cosas, un desafío para la subjetividad construida en el capitalismo. Como afirma Valdés Paz:

En ese espíritu, todo lo personal queda absolutamente pospuesto [...] yo estaba involucrado en una historia y en una tarea trascendental, no tenía sentido ahí la individualidad, se disolvía totalmente.

A esto se suma, en muchos cubanos, cierta sensación de "deuda" con aquellos que se habían jugado la vida en la lucha revolucionaria. Sentimiento que Nicolás Guillén (1971) plasmaría en una frase contundente: “QQuién que no oiga silbar el plomo ni huela el humo de los fusiles estará en situación de castigar o perdonar, es decir de juzgar?" 
Así lo recuerda también Valdés Paz:

Con el triunfo de la revolución y la heroicidad y los barbudos y todo lo que tu sabes, se crea un clima para la juventud de que [...] una especie de deuda moral, que no habíamos hecho lo suficiente, frente a la heroicidad, los barbudos, los muertos, los mártires, etcétera, había una parte de la población que sentíamos que no nos habíamos involucrado lo suficiente, no éramos lo suficientemente heroicos. Y entonces existía un espíritu de compromiso muy alto que estaba reforzado por ese sentimiento de que no habíamos hecho lo suficiente [...] por supuesto Fidel "que importa, la Revolución comienza ahora, todos podemos hacer, tendremos tareas revolucionarias que asumir".

Al triunfo de la revolución el problema de fondo para quienes se quedaron para participar de la construcción revolucionaria era cómo seguir operando con la crítica sin atentar contra el propio proceso que se busca defender.

Como señalábamos, las transformaciones revolucionarias generaron nuevos espacios a los que se incorporaron masivamente muchos cubanos. Aquella "deuda" que motorizó a muchos cubanos a ponerse al servicio de la revolución se conjugó con la falta de profesionales producida por la migración de muchos de ellos, de clases más pudientes, dejando espacios que fueron progresivamente cubiertos por quienes decidieron quedarse en Cuba. Muchos de ellos no contaban con experiencia previa en las tareas que se les asignaban, por lo que tuvieron que aprender sobre la marcha todo aquello que las necesidades del nuevo trabajo impusieran. La experiencia de Alonso es bien ilustrativa en este sentido:

Los que podían tener un dominio de management, de gestión empresarial, habían empezado a salir de las empresas en donde trabajaban, buscando otras vías. [...] Obtengo empleo en una compañía de seguros norteamericana, empiezo a trabajar en septiembre, octubre, por ahí [...] Y por la noche me matriculo en Derecho, que era la carrera que me gustaba [...] A mí se me entorpece la carrera porque cuando se crea el Ministerio de Industria, y las nacionalizaciones, la presión del trabajo es descomunal, para los que estábamos ahí. Yo hubo un momento en el que administraba 6 o 7 empresas, pequeñas, casi todas.

Además del sector empresarial, hubo la necesidad de una educación que respondiera a las nuevas realidades revolucionarias. En 1962, luego de que Fidel proclamara el carácter socialista de la revolución, comienza a enseñarse marxismo en la universidad. 
Al igual que en los sectores empresariales, no había, por razones lógicas, especialistas en la materia que contaran con trayectoria de enseñanza marxista en Cuba. Para hacer frente a esta nueva demanda se convoca a una serie de personas que contaran con algunas herramientas básicas para comenzar a organizar esta tarea. Asi es convocado Alonso:

Ya yo era un estudiante comprometido, militante, con más background que la media de los estudiantes que estaban en la universidad, porque ya yo tenía estudios en los Estados Unidos, había leído a Trotsky. Había empezado a hacer lecturas marxistas. Y además tenía un background también sociológico norteamericano, había estudiado mucho sociología, psicología, etcétera. Y además tenía buena parte de la carrera de derecho hecha, entonces estaba en curso de ciencias políticas pero estaba en derecho también. Entonces bueno, cuando hacen la selección, pues enseguida nos hicieron la propuesta y yo la acepté porque estaba la idea de dedicarme a la vida intelectual.

El sector universitario no era el único que debía incorporar nuevos docentes. Recordemos que al momento del triunfo de la revolución los niveles de analfabetismo en Cuba afectaban a cerca de un millón de cubanos, llegando a implicar cerca del 45\% de la población rural. Además de la conocida Campaña Nacional de Alfabetización en 1961, hubo en 1960 un llamado de Fidel a estudiantes secundarios para desempeñarse como maestros en la montaña. El movimiento se conoció con el nombre de "Maestros Voluntarios" y operó principalmente en la zona de Sierra Maestra. Allí decide incorporarse Valdés Paz:

Tuve el privilegio de estar en el primer contingente. Antes de la campaña de alfabetización, la campaña de alfabetización comenzó en el año 61 y esto es febrero o marzo del 60 [...] imagínate para un habanero adaptarte a la montaña.

Pero en los primeros años de la revolución, la planificación de estas iniciativas estuvo muchas veces condicionada por las tareas que se iban suscitando sobre la marcha y que en muchos casos determinaron trayectorias complejas como la que tuvo Valdés Paz. La cita es extensa, pero permite ver a través del propio relato la complejidad de aquellos años y la forma en que algunas trayectorias intelectuales fueron atravesadas por contingencias menos vinculadas a lo estrictamente intelectual: Estoy esperando mi ubicación en las aulas de la montaña y me informan de que ya no me voy para la montaña sino que voy a 
ser destinado al servicio exterior. Porque todos los días alguno de los viejos embajadores se declaraba opositor, parte de la diplomacia de nuestras misiones en el exterior nos traicionaba, todo eso ocurría permanentemente. Y se toma de la decisión de ir a formación emergente de diplomáticos para cubrir [...] ese es el nuevo destino que me dan. Tu te puedes imaginar, yo me había preparado para ser un maestro en la montaña y de pronto iba a ser diplomático. Y tenía que esperar una semana que se iba a abrir una academia para formación de diplomáticos y se me llamaría para que me incorporara ahí [...] Ahí se produce el suceso que te acabo de decir de nacionalización. El tema que se impone al país es de dónde va a sacar a los interventores. Y se decide tomar a todo un grupo de maestros voluntarios que estaban ubicados en aulas, en las fuerzas armadas y otros que estaban en este destino diplomático. Con lo cual mi vida volvió a cambiar, agarré otro curso de vida porque me dieron la tarea de intervenir un central azucarero en la provincia de Las Villas.

Luego, me dan a mí una región con 12 centrales azucareros [...] ese parecía ser mi derrotero, y así hago la segunda zafra [...] entonces estoy convertido [...] en un administrador de la economía, dirigente económico del sector más importante del país. Sorpresivamente, al terminar la segunda zafra del pueblo, en el 62, me dicen que se me ha destinado a la agricultura. Lo cual quiso decir que tuve que salir del sector de la industria, ya se había creado el Ministerio de Industria, los centrales azucareros eran parte del Ministerio de Industria, etcétera, y me pasaban a otra institución, al Instituto Nacional de Reforma Agraria. Y allí me dieron la responsabilidad de unas que se conocían como cooperativas cañeras [...].

Allí inicié una vida agropecuaria inacabable, que me llevó 20 años. Y lo que quedaba era una tenue vocación por aquel mundo de la cultura intelectual. Yo fue siempre un lector de todo, pero tenía una gran vocación por el pensamiento teórico, por la filosofía [...] pero no me causaba ningún trauma, era lo más natural de vivir, hacía mi tarea y aprendía de ese otro mundo, y con un mundo más personal que se consumía en la lectura.

\section{EL DEPARTAMENTO DE FILOSOFÍA Y LA EXPERIENCIA DE PENSAMIENTO CRÍTICO}

Luego de la proclamación del carácter socialista de la revolución, se crea un sistema de escuelas de partido de clara orientación pro soviética y en las cuales se enseñan el marxismo leninismo según los manuales de la Academia de Ciencias de la URSS. Pero la universidad, explica Alonso, 
necesitaba algo que tuviera un tono cultural más amplio. Entonces trajeron dos profesores que [...] eran los niños aquellos que salieron de la Guerra Civil Española, los hijos de los comunistas que fueron llevados a Moscú, los educaron ahí y eso, no perdieron la lengua, ganaron la otra. Y entonces se trajo un muy bueno, que se llamaba Anastasio García; se trajo un psicólogo que manejaba también la filosofía, se llamaba Luís Arana Larrea.

Inmediatamente se decide hacer una selección de aquellos estudiantes que por sus promedios y trayectoria política pudieran incorporarse como profesores de filosofía en la universidad. Se fue formando un Departamento de Filosofía que funcionó entre 1963 y 1971, y en el que confluyeron tanto Alonso, como Valdés Paz y Fernando Martínez Heredia. ${ }^{5}$

Los desafíos culturales hicieron que el Departamento de Filosofía cumpliera diversas tareas además de la docencia. Las búsquedas, los debates y el propio proceso formativo de sus integrantes dieron como resultado la creación de la revista Pensamiento Crítico, dirigida por Martínez Heredia. La revista expresa uno de los puntos más visibles de esa compleja relación entre heterodoxia y ortodoxia que mencionábamos al inicio de este artículo. Su director da cuenta de los motivos que impulsaron el nacimiento de aquella revista.

¿Cómo hacer que el pensamiento de Cuba fuera idóneo para empujar a la revolución hacia adelante, para forzarla a revisarse ella misma, autocriticarse, renovarse, cambiarse, ser superior? Y a la vez, ¿cómo multiplicar las fuerzas con que contaba, que eran tan pequeñas comparadas con las fuerzas del imperialismo, o con las del capitalismo mundial y las capacidades que ejerce sobre cada persona? De esas necesidades y desafíos nació Pensamiento Crítico (MARTÍNEZ HEREDIA, 2008, p. 241).

El propio Fidel alentó el trabajo del departamento y le encomendó la tarea de lograr ediciones cubanas de los clásicos del pensamiento y la literatura universal. A partir de allí, el departamento trabajó extra en el armado de lo que luego sería Edición Revolucionaria, que a inicios de septiembre de 1966 se convirtió en el Instituto del Libro de Cuba.

5 Fernando Martínez Heredia nació en 1939 en la provincia cubana de Sancti Spiritus. Recibió educación secundaria del "Plan Fidel" y fue luego profesor de Filosofía de la Universidad de la Habana. Dirigió el Departamento de Filosofía de dicha universidad y se doctoró en Derecho. Participa de las principales organizaciones de estudio cubanas y es actualmente miembro de la Unión de Escritores y Artistas de Cuba (UNEAC). 
Cómo Martínez Heredia apunta, la Revolución Cubana era una herejía teniendo en cuenta las "vías" que el comunismo soviético predominante planteaba respecto al camino revolucionario. ${ }^{6}$ Pero durante un tiempo esa herejía fue la que posibilitó el crecimiento cultural de la revolución.

La dicotomía entre "oficial" y "disidente" es muy incierta. La revista no fue ni una cosa ni la otra. Fue un gran avance de la revolución dejar de tener una publicación teórico-política oficial, en 1966. La que existía desde 1962 era un calco de las existentes en los llamados países socialistas [...]. No quiero hacer un juego de palabras, pero para nosotros el único sentido que tenía Pensamiento Crítico era expresar un pensamiento propio, y éste está obligado a ser crítico (TORRES, 2007).

Alonso, otro de sus integrantes, aclara: Nunca nos engañamos, nunca nos creímos que éramos profesores universitarios [...] nosotros sabíamos que éramos los resultados precarios de una urgencia. Y que queríamos, a la vez que teníamos que enseñar, teníamos que formarnos. Y agrega: Nos habíamos empezado a dar cuenta que los manuales de filosofía no eran la forma de estudiar la filosofia, que generaban el dogmatismo, que el dogmatismo era algo reproducible.

El fracaso de la zafra de los 10 millones dejó al país exhausto y con una situación económica complicada. La necesidad de incrementar la ayuda soviética llevó a un desmantelamiento de aquellas iniciativas que, como Pensamiento Crítico, resultaran irreverentes con las líneas del marxismo impuesta por la Unión Soviética. Publicar a Herbert Marcuse, Paul Baran, Ernest Mandel y Sweezy o a Jean Paul Sartre pasó a ser una herejía demasiado pronunciada y la revista fue cerrada en 1971. En palabras de Alonso:

Pensamiento Crítico se cierra en un momento en que la economía del país está muy deteriorada, está muy en bancarrota. La zafra de los 10 millones fracasa [...] entonces ahí ya lo que va a haber es un giro de posición, es decir, Cuba se ve en la necesidad de renunciar a mantener la búsqueda de un socialismo autóctono y optar por la propuesta soviética. Eso le permite entrar en el sistema complejo del CAME.

Valdés Paz había incorporado más tardíamente a la experiencia. Después de años de trabajo en agricultura, se crea la

6 Entrevista de Julio César Guanche a Martínez Heredia, en Cubaliteraria. Portal de Literatura Cubana. Disponible en http://www.cubaliteraria.cu/autor/fernando_martinez_heredia/works/interviews/guanche.htm 
circunstancia [...] de salirme de la agricultura [interrupción] y paso a la universidad como profesor del Departamento de Filosofía en la universidad. Que era un departamento emblemático por la historia cultural del país, el Departamento de Filosofía fue el centro de la heterodoxia cultural en aquel período.

La experiencia del Departamento de Filosofía cierra al finalizar un ciclo en la revolución, y en el que se inicia un mayor acercamiento con la Unión Soviética. La "heterodoxia" imperante en la experiencia del grupo, con posiciones que se alejaban de las directivas soviéticas, determinó el cese del apoyo de la dirección política cubana al proyecto y la adopción de posiciones pro-soviéticas, dando inicio a un período recordado por algunos autores como el "quinquenio gris".

\section{COMENTARIOS FINALES}

Si bien en cada caso las trayectorias individuales previas a la revolución difieren, puede observarse como factor común que las necesidades impuestas primaron por sobre los contenidos de lo que cada uno de ellos traía ya como bagaje intelectual en el transcurso de ese proceso. La revolución, en cierta forma, planteaba antes que nada una revolución subjetiva; las vivencias adquiridas y las proyecciones sobre el futuro individual se redefinieron por imposición de las nuevas circunstancias.

Las búsquedas desatadas por esa revolución subjetiva, por las nuevas preguntas planteadas por la naciente revolución, posibilitaron también la emergencia de nichos de pensamiento heterodoxo cuya suerte estará, una vez más, atada a las necesidades propias de la revolución. En este sentido, los testimonios recogidos en este artículo apuntan a una misma dirección: al momento de la revolución, las expectativas personales (o los "egos" tan particularmente desarrollados en los intelectuales) no fueron dejadas de lado, pero quedaron claramente subordinadas a las necesidades planteadas por un proceso colectivo. Y el tan renombrado "origen pequeño burgués" de algunos intelectuales no resultó un factor excluyente para la inserción en el proyecto revolucionario.

La relación entre la revolución y el intelectual (tantas veces definida de antemano por la teoría) se mostró redefinida cuando aquella revolución ideal se trasladó al plano de lo concreto. De la misma forma, la relación entre la heterodoxia y la ortodoxia no 
siguió un único cauce lineal, sino que se combinó en diferentes momentos para dar respuesta a las necesidades propias del proceso. En otras palabras, cuando el pensamiento heterodoxo resultó fundamental para la elaboración de nuevas interpretaciones tuvo un lugar central en la "orientación" del proceso.

Desde esta perspectiva, el hecho de no haber sido una revista "oficial" fue beneficioso para el proceso cubano porque le permitía ampliar los márgenes de la polémica en las búsquedas para la constitución de un pensamiento diferente. En palabras de Martínez Heredia: "No quiero hacer un juego de palabras, pero para nosotros el único sentido que tenía Pensamiento Crítico era expresar un pensamiento propio, y éste está obligado a ser crítico" (TORRES, 2007). ${ }^{7}$

La relación entre heterodoxia y ortodoxia vuelve a redefinirse entrada la década de 1970, en el marco de lo que Ambrosio Fornet bautizó como "quinquenio gris". Pero tal como lo indicara uno de los entrevistados de este artículo, ese momento cierra un ciclo en la Revolución Cubana, con características marcadamente distintas a las del período anterior y que ameritaría un desarrollo aparte. ${ }^{8}$

7 En esta misma línea, escribe Retamar en la Revista Casa de Las Américas, número 40, de enero-febrero de 1967: No basta adherir verbalmente a la revolución para ser un intelectual revolucionario, ni siquiera basta con realizar las acciones de un revolucionario, desde el trabajo agrícola hasta la defensa del país, aunque ésas sean condiciones sine qua non. Ese intelectual está obligado también a asumir una posición intelectual revolucionaria.

8 Para una visión sobre el tema, es fundamental la lectura de la conferencia que el propio Fornet brindó en Casa de Las Américas el 30 de enero del año 2007. La misma puede consultarse en http://www.criterios.es/pdf/fornetquinqueniogris.pdf 


\section{REFERENCIAS}

GILMAN, Claudia. Entre la pluma y el fusil. Buenos Aires: Siglo XXI, 2003.

GUILLÉN, Nicolás. Sobre el congreso y algo más. Verde Olivo, Havana, n. 22, 30 mayo 1971).

MARTÍNEZ HEREDIA, Fernando. A cuarenta años de pensamiento crítico. Crítica y emancipación: Revista latinoamericana de Ciencias Sociales, Buenos Aires, año 1, n. 1, jun. 2008. Disponible en: <http://bibliotecavirtual.clacso.org.ar/ar/libros/secret/CyE/ cye6S5.pdf>.

TORRES, Carlos. Pensamiento crítico, trinchera de ideas. Punto Final, Santiago, edición 634, mar. 2007. Disponible en: <http:// www.puntofinal.cl/634/pensamientocritico.htm>. 